\title{
Organisational factors and academic research agendas: an analysis of academics in the social sciences
}

Hugo Horta ${ }^{\mathrm{a}}$ and João M. Santos ${ }^{\mathrm{b} *}$

${ }^{a}$ Faculty of Education, The University of Hong Kong, Pokfulam, Hong Kong SAR, China; ${ }^{b}$ Instituto Universitário de Lisboa (ISCTE-IUL), Centro de Investigação e Intervenção Social (CIS-IUL), Lisbon, Portugal

* Corresponding author. Tel: (+351) 21790 3000. E-mail address: joao_marques_santos@iscte-iul.pt (João M. Santos).

\section{Funding}

This work was supported by doctoral grant PD/BD/113999/2015 from the Fundação para a Ciência e Tecnologia and co-funded by the European Social Fund and the Portuguese Ministry of Science and Education; the research was also funded by the Research Grants Council (Hong Kong) through a project entitled 'Characterising researchers' research agenda-setting: an international perspective across fields of knowledge' (project number: 27608516). 


\title{
Organisational factors and academic research agendas: an analysis of academics in the social sciences
}

\begin{abstract}
Academic research demands placed on contemporary universities are strongly related to the production of breakthrough research. Both governments and university management strive to make the production of academic research more cost-efficient and have implemented measures to ensure this. Top-down policies influenced by new public management and managerialism have been introduced, pushing for competitiveness and performativity in academic research setups. These policies and guidelines have been criticised by academics as having eroded collegiality and autonomy, which are considered necessary to achieve quality research. The focus of this study is on social sciences and aligns with this critique, demonstrating that autonomy and collegiality are the key organisational features in fostering multidisciplinary, collaborative and riskier research agendas leading to breakthroughs. Academics with high levels of organisational commitment are more likely to create research agendas that assume more conservative, discipline bound and risk-averse traits, having less potential to derive the intended research.
\end{abstract}

Keywords: autonomy; academic research; social sciences; research agendas; collegiality

\section{Introduction}

Research performance ${ }^{1}$ has an increasingly central role in defining the prestige of contemporary universities and affects the level of resources academics can obtain for

\footnotetext{
${ }^{1}$ Research performance is defined and measured by bibliometric outputs, such as publications and citations produced over a given time, and often associated with national and organisation-related incentives, targets and expectations (see Langfeldt et al., 2015; Hicks, 2012; Bazeley, 2010).
} 
their research (Munch, 2014). Academics and their work are now closely scrutinised as calls for more accountability and transparency have been voiced, alongside government policies to ensure public expenditure in higher education is more efficient (Olssen, 2016). This efficiency drive is often linked to public budget constraints or to the reluctance of politicians to further increase funding for research, but it also demonstrates an increasing lack of trust in the work developed in universities and by academics (Woelert and Yates, 2015). Aligned with this is a shift in the perception and image of academia, in which the 'ivory tower' idea has been replaced by universities portraying themselves as entrepreneurial and more engaged with and attentive to societal needs (Pinheiro and Stensaker, 2014). Increased accountability and the need for efficiency have led to more competitive funding schemes for research, which encourage further collaboration and specify expected outputs such as publications in international English language peer-reviewed journals and outcomes that focus on the potential for practice and policy (Chubb and Watermeyer, 2017). A culture of measurement and performance has thus been established in universities and continues to be driven forward by university and departmental leaders, often in a top-down style that increasingly conflicts with academic autonomy and collegiality and that strives for improvements in the quality and practical use of research outputs (Sutton, 2017).

Research performance has become central to both academics beginning their careers and those facing tenure and promotion (Hammarfelt and Rushforth, 2017). Research productivity indicators, both old and new, are now commonly used to assess the evolving research performance of academics in increasingly competitive environments under the new dynamics of academic capitalism (Kyvik and Aksnes, 2015). This has influenced the way academic work is developed in universities by accelerating the research processes and highlighting the importance of deliverables from 
academic research (Levin and Aliyeva, 2015). Thus, it represents the triumph of Mertonian logic, and the full realisation by policy makers and institutional leaders that extrinsic motivations, as responses to field positioning and organisational incentives, function better as drivers of research engagement and production than the inner motivations of academics (Long and Krauze, 1982). Departmental management styles, leadership and culture that influence the attitudes of individual academics towards research further underline the effect of the environment on individual motivators (Edgar and Geare, 2013).

The increasingly competitive worldwide regime in which academic research is conducted, and the rise of performativity ${ }^{2}$ as part of a set of policies intended to promote research breakthroughs and 'useful' knowledge, has been debated and analysed from several perspectives. However, the association of organisational characteristics with factors that influence the design and orientation of individual academics' research agendas has not yet been examined. Thus, the research question addressed in this study is as follows: how are organisational factors related to the working research environments of universities associated with the research agendas of academics in the social sciences? The novelty of this study is that instead of focusing on how the current

\footnotetext{
${ }^{2}$ This study uses the definition of performativity suggested by Ball (2003). Ball defines performativity as 'a technology, a culture and a mode of regulation that employs judgements, comparisons and displays as means of incentive, control, attrition and change based on rewards and sanctions (both material and symbolic). The performances (of individual subjects or organisations) serve as measures of productivity or output, or displays of 'quality', or 'moments' of promotion or inspection. As such they stand for, encapsulate or represent the worth, quality or value of an individual or organisation within a field of judgement' (2003: 216).
} 
organisational characteristics of departments/universities influence research outputs, the focus is on how these characteristics are associated with the research orientation decisions of academics. The analysis also reveals the extent to which the drivers behind managerial changes that are oriented towards more top-down management styles and research constraints are aligned with the expectations of transforming academic research so it is more multidisciplinary, collaborative and innovative. The analysis focuses on the social sciences field of higher education studies, as this includes a broad range of disciplines and hence many academics from different fields participate in it (Horta and Jung, 2014; Tight, 2013). In addition, top-down management policies, performativity practices and organisational influences on the research in this contemporary academic environment are commonly drawn from the hard sciences, and thus affect social scientists more significantly (Hammarfelt and Rushforth, 2017).

The remainder of this paper is organised as follows: the next section presents a brief literature review on the changing organisational characteristics influencing academic research in modern universities and the factors influencing the research agendas of academics. The methods section follows, and the empirical data are presented and discussed in the findings section. The last section concludes the article.

\section{Literature review}

Organisation of contemporary academic research: new public management, managerialism and performativity

In response to a growing audit culture and increasing related government policies and competition, universities are adapting their structures and management styles and developing incentives organised around the logics of managerialism and new public 
management, which promote idealised concepts of corporate efficiency to enhance academic research performance and impact (e.g., Deem et al., 2008). The rules and guidelines of funding agencies, and the top-down management approaches of universities and departments that influence academic research activities, can interfere with the autonomy of academics, and thus their identification with the universities diminishes (Degn, 2018; Winter, 2009). In adopting bureaucratic-led performativity models, which have become central to the functioning of contemporary universities, evaluations and performance rationales become largely driven by simplistic indicators that cannot encompass the complexity associated with academic labour. This complexity includes a creative and serendipitous activity that demands much time and energy: i.e., research (Sutton, 2017). Performativity and its associated indicators become frameworks of judgement that measure the efficiency and productivity of academic labour (Hammarfelt and Rushforth, 2017; Ball, 2012). In this model, academics become exposed to nebulous and sometimes unrealistic corporate-minded priorities, and to shifting goalposts and whims that place them in positions of vulnerability, thus reducing their agency, autonomy and freedom (Oleksiyenko and Tierney, 2018).

The effects of this can then extend to a decreasing level of collegiality, which particularly affects early-career academics who are more vulnerable to the termination of contracts and more concerned with surviving/thriving in competitive environments that emphasise the role of individual success over other priorities (Giroux, 2016; Schrecker, 2012). The introduction of managerialism may also lead to this potential decrease in collegiality, which according to Yokohama (2006) is at the opposite extreme of the same continuum, as it institutionalises competition among colleagues. The author suggests that the values of collegiality are embedded within the academic community 
and its management characteristics are associated with informality, trust and low levels of hierarchy, but the values of managerialism involve strategies that are to a large extent dictated by external stakeholders, hierarchy, formality and assessment. The locus of power also rests with institutional leadership and centralised committees (Yokohama, 2006). However, the introduction of new public management, managerialism and performativity was intended by policy makers and university management to transform academic research so that the best were rewarded and that the research improved and was more effective. These transformations have certainly led to a greater number of publications and citations (Beerkens, 2013), and if the organisational incentives and managerial practices are focused on producing more publications, then academics (like anyone else in society) are bound to adapt to survive and eventually thrive, resulting in greater research output in terms of both the individual and the university (Brew and Lucas, 2009).

However, academics are known to conform to the characteristics of their organisational context (Long and McGinnis, 1981), so regarding these outcomes as solely or mainly resulting from managerial practices may be somewhat simplistic, ${ }^{3}$ and many other factors may be involved. Growing numbers of academics become more qualified and collaborative, more involved in research and dedicate more time to it (often to the detriment of teaching). To gain more visibility and to receive more citations, they are likely to publish articles in journals indexed by Scopus or the Web of Science rather than books or book chapters. Increases in research funding (national and

\footnotetext{
${ }^{3}$ Outcomes of the new public management, managerialism and performativity environment in academia were the fostering of industry-university collaborations and a greater engagement with civil society (Alexander et al., 2015). This led to the emergence of a new academic engagement with society, where some academics started to collaborate more with non-academic organisations, but also found the incentives to create start-ups with peers and former and current doctoral students (Perkmann et al., 2013). These processes combined a multitude of funding streams to set up new research agendas, some more related to learning, others to access to research funding, others to access to in-kind resources and others to commercialisation (D'Este and Perkmann, 2011). They become a new category of academics, known as entrepreneurial academics and academic entrepreneurs, who share academia with traditional academics.
} 
institutional) and the size of research teams at universities that include more postdocs and $\mathrm{PhD}$ students who contribute to the research effort also have an effect (Júnior et al., 2018; Leisyte, 2016; Kwiek, 2016; Verbree et al., 2015). All of these organisational factors are known to positively affect research productivity (Carayol and Matt, 2004), particularly for academics based in research-oriented universities (Cattaneo et al., 2016), who have a greater capacity for research and a long-established research-focused culture (Verbree et al., 2015).

However, some organisational factors may not have a simple relationship with research productivity. The literature has demonstrated that size and team composition affect non-linearly both research productivity and novelty (Lee et al., 2015; Horta and Lacy, 2011). Increasing levels of managerialism in research governance have also exacerbated the bureaucratisation of research processes at organisational and individual levels, and has been found to negatively affect research productivity (Bacini et al., 2014), while also fostering the division of labour, industrialisation of academic careers and output, and standardisation of research (Walsh and Lee, 2015).

Other studies show that the quality of research productivity is undermined by performativity and management-by-results, as these constrain the intrinsic motivations of academics to engage in creative knowledge-intensive work (e.g, Kallio and Kallio, 2014), and are not conducive to research environments that strive for good research performance and have the characteristics of autonomy, egalitarianism and a strong cultural ethos that supports achievement and individualism (Edgar and Geare, 2013). The short-sightedness of policy makers in implementing policies that appear to ignore academic ethos and culture has been criticised, as this can lead to more output but less ground-breaking research being produced (e.g., Young, 2015). These analyses focus mainly on academic work, resources (competition) and research productivity, but 
overlook how organisational traits are associated with factors influencing the orientations of individual academics' research agendas.

\section{Academic research organisation and the potential influence on the research agendas of academics}

A research activity begins with deciding on a research agenda (e.g., choosing a topic associated with a scientific challenge and deciding on how to pursue it). Academics' research agendas are a combination of individual interests shaped by narrow dimensions associated with the challenges of specifically doing the research from a conceptual and methodological standpoint, and of broader dimensions consisting of environmental, social and individual characteristics and interests, which influence the type of research engagement (Santos and Horta, 2018). Research agendas, as part of the broad academic research process, represent an activity framed by an institutional context and are shaped by institutional values, norms and resources (Bazeley, 2010). For example, universities/departments that highlight the importance of research grant funding may condition academics to pursue research agendas that funding agencies consider to be of strategic importance, and thus more advantageous from a financial standpoint (Leisyte and Dee, 2012). Conformity to the institutional environment and the availability of resources in the department/university (Ebadi and Schiffauerova, 2015) can be critical in defining a research agenda, as can individual attitudes towards risk (Hillson and Murray-Webster, 2007). Leisyte (2007) shows that academics typically adapt to shifting institutional environments by taking a conservative stance and a posture of compliance with the institutional norms, aiming to reduce uncertainty while maintaining stability and thus safeguarding access to resources. Other studies also suggest that academics may adopt conservative stances and conform to the institutional environment due to 
career considerations (Rzhetsky et al., 2015).

Performativity and managerialism practices that increase vulnerability and introduce great uncertainty into the environment are also bound to influence academics, particularly those early in their careers. They may opt for 'safer' research agendas where funding is available, which tend to be of a disciplinary nature characterised by greater conformity and a conservative outlook (Smith, 2017). More disruptive types of research agendas may be perceived as too risky and strategically unsound (Young, 2015). This can also lead senior academics to adapt their research profile strategically to the departments/university's expectations, and thus they assume a more conservative and conforming stance to survive and thrive (Acker and Webber, 2017). The association of factors determining academics' research agendas with the organisational settings of universities may involve two other potentially significant issues. The first concerns the pressure exerted on the teaching research nexus by the need to publish and obtain grants, which takes time. This competes with the time required to focus on teaching and on students, and the new public management processes have exacerbated this dilemma (Leisyte, 2016). The second issue is the undermining of the autonomy of academics and their freedom to research what they choose and how, which is central to much of the literature cited in this article. The organisational settings of contemporary universities suggest that this autonomy is being reduced, and replaced by compliance with the new rules of the game (i.e., the regulated autonomy). This is associated with performativity and the escalating competition for more funding to publish more papers and present the case for greater impact (Oleksiyenko and Tierney, 2018; Leathwood and Read, 2013). The issue of professional autonomy is particularly relevant to the research agendas of academics, as it relates to having agency (or not) in departmental/university settings 
(Stromquist, 2017), and because research is ultimately a matter of personal choice (Polanyi, 2000).

As research activities (including research agendas) result from an interplay between the academic and the university (i.e., the organisation), the analysis in this study is guided by Bandura's (1978) social cognitive theory. This theoretical framework considers three combined factors that have a reciprocal effect (i.e., triadic reciprocity): personal, behavioural, and environmental. Individual research agendas are situated in the behavioural factor, as they relate to decisions and consequent actions that academics take when considering personal preferences and choices (Polanyi, 2012). They are influenced by personal characteristics such as age, gender or personality traits (Baccini et al., 2014), and by environmental characteristics, related to perceived values, norms and taken-for-granted attitudes (Edgar and Geare, 2013; Long and McGinnis, 1981). The organisational aspects are represented by the environmental factor, as they refer to how organisational structures, incentives and dispositions guide behaviours and shape considerations around personal characteristics (see Leisyte, 2016; Fox and Mohapatra, 2007). These two factors are central to the study in terms of its research question. The personal factor is also relevant and accounted for, but is mainly used to control the associations between organisational aspects (the environmental factor) and academics' research agendas (the behavioural factor).

\section{Method}

Combining two inventories: research agendas and organisational traits of research workplaces

Few studies focus on factors influencing the research agendas of academics, but a 
framework for examining them has been designed based on eight dimensions (Horta and Santos, 2016). 1) Scientific ambition is associated with the willingness to be recognised in a field of knowledge and thus to obtain prestige and increased access to resources, and other material and immaterial gains (Bourdieu, 1999). This is associated with the drive to publish as a way to establish recognition through the effects of the cumulative advantage hypothesis in science (Long and Krauze, 1982). 2) Convergence refers to a preference for disciplinary bounded research agendas, and indicates a preference to avoid shifting the foci of research (stability) and to master a specific topic under research (mastery). 3) Divergence refers to a preference for research agendas that address themes from a multidisciplinary perspective (Shut et al., 2014), and involves a willingness to explore multiple research topics (branching out) and a preference for multidisciplinary work. Both convergence and divergence may be conditioned by departmental/university environments (Leisyte, 2016, 2007). 4) Discovery is associated with a preference for a risk-inclined research agenda, manifested in the choice of research topic or a propensity for emerging topics with uncertain outcomes. 5) Conservative refers to a risk-aversion preference for research, and to choosing topics and fields well covered in the literature where uncertainty is less prevalent. Leaning towards a discovery or a conservative approach is not necessarily a matter of preference but rather one of risk management (Cummings and Kiesler, 2015). 6) Tolerance to low funding is a measure of the risk tolerance associated with opting for a research focus that may have very little funding and is expected to be sensitive to organisational pressure towards the acquisition of competitive research funding (Ion and Castro Ceacero, 2017). 7) Collaboration refers to the interest in engaging in collaborative research agendas and can be influenced by institutional pressure to collaborate, but can be a desirable option that furthers access to resources (Ebadi and Schiffauerova, 2015), 
increases research productivity and its quality (Mamun and Rahman, 2015) and fosters career prospects (Hoffman et al., 2014). Engagement in collaborative research agendas may result from a willingness to collaborate, an invitation to collaborate, or both, and is affected by managerial models that actively foster collaborative endeavours (Towns et al., 2014). 8) Mentor influence refers to the degree to which individual research agendas are influenced by the $\mathrm{PhD}$ supervisor, and is expected to decrease over the lifespan of an academic career (Platow, 2012).

Whilst studies on the research agendas of academics are limited, many organisational studies focus on the research workplace (e.g., Perkmann and Walsh, 2008; Leisyte et al., 2008). The Multi-Dimensional University Research Workplace Inventory is a recently created validating instrument used to measure the working research environment in universities (Santos, 2017). It consists of five dimensions and eight sub-dimensions and is used in the analysis of this study.

The first dimension is organisational commitment, which is a staple of organisational research and is used in various contexts, and several similar models appear in the literature (e.g., Meyer and Allen, 1991). Organisational commitment refers to the degree to which an individual identifies with and is committed to an organisation. This dimension is sub-divided into belonging, reflecting the degree to which an individual's identity is aligned with that of his organisation, and the willingness to stay, which is the manifest desire to remain in the current organisation. These two dimensions are similar to concepts in other frameworks, such as affective and continuance commitment in Meyer and Allen's (1991) three component model, and attitudinal and behavioural commitment in the framework of Mowday et al. (1979). The dimension also has a third sub-dimension: satisfaction with the leadership, which reflects the literature suggesting that leadership has a substantial impact on 
organisational commitment (e.g., Avolio et al., 2004). The second dimension, resources, reflects the academic perception of access to resources in the department/university, which has been found to affect research productivity (CastroCeacero and Ion, 2018) and the lowering of satisfaction levels, as academics may need to choose topics that are not aligned with their interests (Henkel, 2000). The third dimension is social satisfaction, which refers to the level of satisfaction the academic has for his colleagues. This is also a measure of collegiality, encompassing the perceived professional benefits obtained from colleagues (thus the quality and collegiality of the organisation is also scrutinised here; see Postiglione and Jung, 2015). The fourth dimension is autonomy, that is, the perceived level of autonomy the academic believes to have in the department/university. In this framework, autonomy is the relative amount of independence granted to the individual regarding how work should be conducted and is an essential dimension as it is necessary in creativity driven environments (Hemlin et al., 2008). Autonomy is strongly related to the fifth and final dimension, unconstraint, which measures the lack of institutional constraints and obligations unrelated to research (particularly teaching). Both dimensions are associated with the existence (or lack of) perceived hierarchical constraints, which are known to hinder the freedom to conduct research (Latour and Woolgar, 2013), and feelings of a lack of academic empowerment within the department/university (Henkel, 2000).

\section{Participants}

The analysis in this study is based on data obtained via an online survey conducted between May and November 2015. The procedure for data collection was first to identify the corresponding authors of all articles published in Scopus-indexed Higher 
Education journals in the past 10 years. ${ }^{4}$ These authors were then invited to participate in the online questionnaire. After accepting the invitation, they were asked to sign an informed consent form before they could participate in the study.

The questionnaire began with a set of demographical questions, followed by a series of instruments. First, the Multi-Dimensional Research Agendas Inventory (MDRAI) was included, comprising 35 Likert-style questions aimed at evaluating various aspects of the participants' research agendas measured in 8 dimensions (Horta and Santos, 2016). The second instrument, the Multi-Dimensional University Research Workplace Inventory (MDURWI), measures organisational features of an academic research workplace. This is comprised of 27 items organised into 5 dimensions, of

\footnotetext{
${ }^{4}$ The study was preceded by a pilot study that enabled the authors to conclude that a 10 -year
} time-frame to identify authors was optimal for the analysis. The pilot was also useful in improving the structure, content and focus of the questionnaire. The analytical focus was on higher education journals, for three main reasons. 1) These journals are identified with the social sciences and academics from all disciplinary fields of the social sciences participate in them. Frequently, papers in higher education journals are published by sociologists, psychologists, economists, management and operation research researchers, philosophers, anthropologists and others. This is evidenced by analyses of the fields that include a multitude of theoretical and methodological approaches from all social sciences (see Tight, 2013). 2) It is an internationalised field, and one where substantial collaborations of social scientists from different backgrounds are found, working together and thus raising the incidence of multidisciplinary and interdisciplinary studies. Higher education journals thus combine both disciplinary, multidisciplinary and interdisciplinary publications, some arising from collaborations (Tight, 2013). 3) The authors are familiar with the field of higher education studies and with higher education journals, ensuring a higher degree of data sensibility in the analysis. 
which 1 can be de-aggregated into 3 sub-dimensions (Santos, 2017). A third instrument was also included - the BFI-10 questionnaire, which evaluates personality traits using the Big Five framework (Rammstedt and John, 2007). This was mainly included for exploratory purposes, and to add value to the analysis by controlling for the personality of academics in relation to the research agendas they choose.

A total of 1,348 researchers agreed to participate in this study. However, 613 were excluded due to their failure to complete the required instruments, resulting in a final sample size of 735 participants with complete data. The large number of participants who dropped out was mainly due to the length of the survey, which took up to 40 minutes to complete, an issue that was noted by a few participants in the comments box at the end of the survey. This final sample was reasonably divided between females $(53.7 \% ; \mathrm{N}=395)$ and males $(46.3 \% ; \mathrm{N}=340)$. The participant's ages ranged from 24 to 84 years $(M=50.64 ; S D=10.95)$. Finally, in terms of geographical distribution, the majority of participants were based in the United States $(24.9 \% ; \mathrm{N}=$ 183), followed by Australia (15.5\%; $\mathrm{N}=114)$ and the United Kingdom $(13.7 \% ; \mathrm{N}=$ 101), with the remainder distributed in other countries. They all experienced identical neo-liberal performativity related reforms and pressures towards academic research, which condition their research engagement. The full list of participating countries is given in Appendix A.

\section{Variables}

The dependent variables in this study were the eight dimensions of the MDRAI, and the explanatory variables were the seven sub-dimensions of the MDURWI. The five traits from the BFI-10 inventory were used as the control variables. These are openness to experience, which can be broadly considered as a preference for novelty and new 
experiences; conscientiousness, a measure of meticulousness and organisation; extraversion, measuring how outgoing the individual is; agreeableness, reflecting the degree of cooperation exhibited by the individual; and neuroticism, which is a measure of emotional stability. Other control variables were age, gender and early career, a dummy variable indicating whether the researcher is early $(<40$ years old $)$ or late in his career (> 40 years old), following the cut-off proposed in the literature (Bazeley, 2003). Research oriented university was also included as a control variable, aimed at controlling for differences derived from the host institution; this is a dummy variable that assumes the value of 1 if the participant's institution is ranked in the top 500 universities of the Shanghai World University Ranking, and 0 otherwise. A further variable, hard-soft, was included. This is a continuous variable ranging from -1 to 1 and indicates the relative weight of articles published by the author on fields considered as 'hard science' (-1) or 'soft science' (1). This was computed by adding all of the articles published in soft science fields such as social sciences, and subtracting all articles published in hard science fields such as engineering, and then dividing the result by the total number of articles published. Authors contributing to the social sciences do not necessarily have a complete background in the field and may publish in and outside the social sciences (as happens in the field of higher education studies; see Horta and Jung, 2014). Finally, included but not shown in the tables (for the sake of readability) were country variables operating as fixed effects ${ }^{5}$.

\section{Procedure}

Due to the continuous nature of the dependent variables, a multivariate ordinary least squares model was used for this analysis (Hair et al., 2007) and qualitative predictors

\footnotetext{
${ }^{5}$ Countries with 10 or less respondents were aggregated in a single category, i.e, Others.
} 
were coded as dummies to enable it to be used in the regression equation.

\section{Results}

The findings are given in Table 1. Most significantly, autonomy was found to be the most relevant condition for academics in the social sciences, enabling them to develop ambitious, multidisciplinary, collaborative and risk-taking research agendas, with the highest potential for research breakthroughs. Autonomy has a positive impact on ambition, divergence, discovery, collaboration and tolerance to low funding $(\mathrm{p}<0.01 ; \mathrm{p}$ $<0.05$ for discovery and collaboration) and a negative impact on convergence, conservative and mentor influence $(\mathrm{p}<0.01)$. Equally important is the role of social satisfaction, which relates to collegiality. This organisational variable has a positive effect on divergence, discovery, collaboration and mentor influence $(\mathrm{p}<0.05 ; \mathrm{p}<0.01$ for collaboration), variables that again highlight research agendas with characteristics related to risk-taking, collaboration and multidisciplinary work. Thus, they are aligned with policy makers' expectations for research produced in contemporary universities, although not with new public management and managerialism policies that can curtail both autonomy and collegiality (Yokohama, 2006).

Belonging has a modest negative effect on divergence and mentor influence $(\mathrm{p}<$ 0.1). Willingness to stay has much more negative effects on ambition $(\mathrm{p}<0.05)$, divergence $(\mathrm{p}<0.01)$, discovery $(\mathrm{p}<0.1)$ and collaboration $(\mathrm{p}<0.05)$, but positive effects on convergence $(\mathrm{p}<0.01)$ and conservative $(\mathrm{p}<0.01)$. Organisational commitment, including commitment related to following up organisational managerial criteria and policies, may therefore lead to organisational conformity, preventing the emergence of riskier research agendas that lead to potentially disruptive advancements in knowledge and fewer multidisciplinary approaches. The institutional pressure to 
maintain 'safer' avenues of research may lead to this, as the desire of the academic to remain in the institution and to be acquiescent can lead to such conformity.

Other variables present interesting findings, such as the negative impact of unconstraint on divergence $(\mathrm{p}<0.01)$ and collaboration $(\mathrm{p}<0.01)$. The perceived lack of pressure to do work unrelated to research activities decreases the propensity to conduct multidisciplinary and collaborative research endeavours. Although counterintuitive, this can be interpreted as the need for academics to be engaged in other scholarly activities (such as teaching), which may positively influence the design of research agendas (through contact with students and the exchange of ideas with them; see Mitchell and Rebne, 1995). The positive effect of perceived resources on convergence and conservative $(\mathrm{p}<0.1)$ suggests that an abundance of financial resources may lead to setting more conservative research agendas. Thus, despite institutional pressures to apply for research grants, funding for research may not be as critical in the social sciences as it is in other disciplinary fields. The more resources academics in the social sciences perceive they have, the more disciplinary and less risky the research agendas, because the researchers adapt their agendas to the needs of the funding bodies and agencies that are typically disciplinary and conservative by nature (Siler at al., 2015). Finally, satisfaction with the leadership has a limited influence on the research agendas of academics, with only a positive effect on mentor influence ( $\mathrm{p}<$ $0.05)$.

The analysis of the control variables focuses first on the Big Five personality traits. Extraversion is found to be a positive predictor of collaboration ( $\mathrm{p}<0.01)$, because outgoing academics are more able to establish social connections, which is likely to translate into a higher capacity for engaging in scientific collaborations. Conscientiousness has a positive albeit modest impact on ambition $(\mathrm{p}<0.1)$, probably 
reflecting higher degrees of thoughtfulness regarding one's work. Neuroticism has a positive impact on convergence $(\mathrm{p}<0.05)$ and conservative $(\mathrm{p}<0.01)$. This dimension represents emotional instability, but not necessarily to a pathological degree. The relationship does suggest, however, that researchers with less emotional stability may prefer mature fields and may specialise in single topics, in which change and uncertainty are less likely. This is the opposite of openness, which has a negative impact on convergence $(\mathrm{p}<0.01)$ and conservative $(\mathrm{p}<0.01)$, while having a positive impact on divergence $(\mathrm{p}<0.05)$, discovery $(\mathrm{p}<0.01)$ and tolerance to low funding $(\mathrm{p}<0.05)$. Academics with high levels of openness to experience may actively shun more conservative endeavours while seeking riskier ventures and newer topics of research. Agreeableness does not exhibit any significant impact on research agendas.

Male academics lean more towards discovery and tolerance to low funding $(\mathrm{p}<$ 0.05) than females but engage less with collaborative research agendas (collaboration; $\mathrm{p}$ $<0.1)$. Age has no significant impact on the research agendas of academics. Social sciences academics who operate more in 'softer' fields gravitate towards disciplinary endeavours, despite a higher tolerance of the lack of funding and higher scientific ambition [a positive impact on ambition $(\mathrm{p}<0.1)$, convergence $(\mathrm{p}<0.01)$ and tolerance to low funding $(\mathrm{p}<0.01)$ ]. Working in a research-oriented university has a negative effect on tolerance to low funding $(\mathrm{p}<0.05)$, probably because academics in these universities are more used to having the resources available to them that enable them to engage in any research agenda that they may be interested in pursuing, thus making it nonsensical to engage in research agendas with little to no funding available. Finally, the H-index has a positive impact on ambition $(\mathrm{p}<0.01)$ and collaboration $(\mathrm{p}<0.01)$, as the more publications academics have and the more visibility they provide, the more ambitious their research agendas become, along with their desire for collaboration. 


\begin{tabular}{|c|c|c|c|c|c|c|c|c|}
\hline \multicolumn{9}{|c|}{ Table 1: Organisational Factors Effects on Research Agendas } \\
\hline Variables & Ambition & Convergence & Divergence & Discovery & Conservative & TTLF & Collab. & Mentor \\
\hline \multirow[t]{2}{*}{ Unconstraint } & -0.029 & 0.002 & $-0.094 * * *$ & -0.033 & -0.041 & -0.017 & $-0.078 * * *$ & $0.087^{*}$ \\
\hline & $(0.035)$ & $(0.031)$ & $(0.032)$ & $(0.038)$ & $(0.035)$ & $(0.044)$ & $(0.028)$ & $(0.045)$ \\
\hline \multirow[t]{2}{*}{ Autonomy } & $0.123 * * *$ & $-0.117 * * *$ & $0.135 * * *$ & $0.093 * *$ & $-0.140 * * *$ & $0.159 * * *$ & $0.083 * *$ & $-0.185^{* * *}$ \\
\hline & $(0.042)$ & $(0.036)$ & $(0.039)$ & $(0.045)$ & $(0.042)$ & $(0.052)$ & $(0.034)$ & $(0.056)$ \\
\hline \multirow[t]{2}{*}{ Social Satisfaction } & 0.055 & -0.054 & $0.100 * *$ & $0.115^{* *}$ & 0.073 & -0.019 & $0.449 * * *$ & $0.143 * *$ \\
\hline & $(0.052)$ & $(0.045)$ & $(0.048)$ & $(0.056)$ & $(0.052)$ & $(0.065)$ & $(0.042)$ & $(0.066)$ \\
\hline \multirow[t]{2}{*}{ Resources } & 0.0073 & $0.048^{*}$ & -0.049 & 0.044 & $0.063^{*}$ & 0.060 & -0.019 & 0.030 \\
\hline & $(0.033)$ & $(0.029)$ & $(0.030)$ & $(0.036)$ & $(0.033)$ & $(0.041)$ & $(0.027)$ & $(0.043)$ \\
\hline \multirow[t]{2}{*}{ Belonging } & 0.029 & 0.025 & $-0.087^{*}$ & -0.032 & 0.055 & -0.018 & -0.021 & $-0.111^{*}$ \\
\hline & $(0.049)$ & $(0.042)$ & $(0.045)$ & $(0.053)$ & $(0.049)$ & $(0.061)$ & $(0.040)$ & $(0.063)$ \\
\hline \multirow[t]{2}{*}{ Willingness to Stay } & $-0.088 * *$ & $0.080 * *$ & $-0.099 * * *$ & $-0.074^{*}$ & $0.097 * * *$ & 0.008 & $-0.061 * *$ & -0.029 \\
\hline & $(0.036)$ & $(0.031)$ & $(0.033)$ & $(0.039)$ & $(0.036)$ & $(0.045)$ & $(0.029)$ & $(0.047)$ \\
\hline \multirow[t]{2}{*}{ Satisf. Leadership } & -0.026 & 0.041 & 0.001 & -0.030 & -0.010 & 0.052 & -0.003 & $0.107 * *$ \\
\hline & $(0.039)$ & $(0.034)$ & $(0.036)$ & $(0.042)$ & $(0.039)$ & $(0.049)$ & $(0.032)$ & $(0.050)$ \\
\hline \multirow[t]{2}{*}{ Early Career } & $0.315^{* *}$ & 0.139 & -0.120 & 0.104 & 0.071 & -0.114 & -0.057 & $0.470 * * *$ \\
\hline & $(0.127)$ & $(0.112)$ & $(0.118)$ & $(0.138)$ & $(0.128)$ & $(0.160)$ & $(0.104)$ & $(0.164)$ \\
\hline \multirow[t]{2}{*}{ Male } & 0.018 & -0.106 & 0.104 & $0.208 * *$ & -0.020 & $0.245^{* *}$ & $-0.116^{*}$ & 0.090 \\
\hline & $(0.079)$ & $(0.069)$ & $(0.073)$ & $(0.085)$ & $(0.079)$ & $(0.098)$ & $(0.064)$ & $(0.103)$ \\
\hline \multirow[t]{2}{*}{ Age } & -0.002 & 0.006 & -0.006 & 0.005 & -0.009 & -0.005 & -0.003 & -0.005 \\
\hline & $(0.005)$ & $(0.004)$ & $(0.005)$ & $(0.005)$ & $(0.005)$ & $(0.006)$ & $(0.004)$ & $(0.007)$ \\
\hline \multirow[t]{2}{*}{ H-Index } & $0.041 * * *$ & 0.005 & -0.009 & 0.015 & -0.009 & 0.016 & $0.028 * * *$ & -0.015 \\
\hline & (0.009) & $(0.008)$ & $(0.009)$ & $(0.010)$ & $(0.009)$ & $(0.011)$ & $(0.007)$ & $(0.012)$ \\
\hline \multirow[t]{2}{*}{ HardSoft } & $0.150^{*}$ & $0.206^{* * *}$ & $-0.265 * * *$ & -0.006 & 0.076 & $0.459 * * *$ & -0.069 & 0.170 \\
\hline & $(0.081)$ & $(0.071)$ & $(0.075)$ & $(0.0878)$ & $(0.081)$ & $(0.102)$ & $(0.066)$ & $(0.106)$ \\
\hline \multirow[t]{2}{*}{ Research Oriented U. } & 0.121 & 0.059 & 0.007 & -0.041 & 0.018 & $-0.216^{* *}$ & 0.036 & -0.007 \\
\hline & $(0.080)$ & $(0.070)$ & $(0.073)$ & $(0.086)$ & $(0.080)$ & $(0.010)$ & $(0.065)$ & $(0.104)$ \\
\hline \multirow[t]{2}{*}{ Extraversion } & 0.033 & -0.037 & 0.044 & -0.011 & 0.002 & -0.008 & $0.089 * * *$ & 0.042 \\
\hline & $(0.037)$ & $(0.032)$ & $(0.034)$ & $(0.040)$ & $(0.037)$ & $(0.046)$ & $(0.030)$ & $(0.048)$ \\
\hline \multirow[t]{2}{*}{ Agreeableness } & 0.027 & -0.060 & 0.077 & -0.021 & -0.025 & -0.017 & 0.040 & 0.060 \\
\hline & $(0.056)$ & $(0.049)$ & $(0.052)$ & $(0.060)$ & $(0.056)$ & $(0.070)$ & $(0.045)$ & $(0.073)$ \\
\hline \multirow[t]{2}{*}{ Conscientiousness } & $0.113 * *$ & 0.006 & -0.061 & 0.009 & -0.026 & 0.088 & 0.054 & 0.019 \\
\hline & $(0.055)$ & $(0.049)$ & $(0.051)$ & $(0.060)$ & $(0.056)$ & $(0.069)$ & $(0.045)$ & $(0.072)$ \\
\hline \multirow[t]{2}{*}{ Neuroticism } & 0.038 & $0.092 * * *$ & -0.058 & -0.020 & $0.109 * * *$ & -0.003 & -0.034 & 0.068 \\
\hline & $(0.041)$ & $(0.036)$ & $(0.038)$ & $(0.044)$ & $(0.041)$ & $(0.051)$ & $(0.033)$ & $(0.053)$ \\
\hline \multirow[t]{2}{*}{ Openness } & 0.044 & $-0.110 * * *$ & $0.086^{* *}$ & $0.293 * * *$ & $-0.188 * * *$ & $0.117 * *$ & -0.052 & -0.068 \\
\hline & $(0.045)$ & $(0.040)$ & $(0.042)$ & $(0.049)$ & $(0.046)$ & $(0.057)$ & $(0.037)$ & $(0.059)$ \\
\hline Observations & 735 & 735 & 735 & 735 & 732 & 732 & 735 & 678 \\
\hline R-squared & 0.147 & 0.142 & 0.143 & 0.120 & 0.129 & 0.121 & 0.299 & 0.128 \\
\hline
\end{tabular}

Notes: Standard errors in parentheses. $* * * \mathrm{p}<0.01, * * \mathrm{p}<0.05, * \mathrm{p}<0.1$

\section{Conclusion}

This study shows that organisational characteristics are associated with and can

influence the research agendas of academics. This finding is aligned with the results of

other studies emphasising the relevance of the organisational environment in shaping

the research behaviour and output of academics (Leisyte, 2016; Edgar and Geare, 2013).

However, this study further contributes to the critique that policies that attempt to 
condition and regulate the research produced by academics, and encourage the production of breakthrough research, may be counterproductive and may have the opposite effect to what policy makers and university managers intend (an argument also put forward by Young, 2015). Our findings show that from an organisational standpoint, giving more autonomy to academics and immersing them in a collegial environment encourages the development of research agendas that are bound to be more multidisciplinary, collaborative and disruptive. Their agendas are therefore also more risk-taking and thus having the potential to garner unexpected and high-value findings (although they may also lead to failure, which is normal in research processes and a requirement for knowledge advancement; see Firestein, 2015). In addition, the more autonomy academics feel they have in their organisations, the more ambitious in terms of research agenda they become, and thus they are potentially more productive in terms of research output and more determined to be recognised by their field community. This resonates with the classical literature on science and technology, which suggests that academics should be free to pursue their own topics and to operate relatively independently of outside influences (Polanyi, 2000).

However, universities that have implemented new public management and managerialism practices in their research organisations undermine these two important organisational traits in academic research (e.g., Oleksiyenko and Tierney, 2018; Hammarfelt and Rushforth, 2017; Ball, 2012; Yokohama, 2006). The findings highlight the importance of organisational traits and policies for academics' research agendas, and the caution (and probable need for constant assessment) required from those implementing them. The impact of resources and commitment in the context of conservative and convergent agendas of academics in the social sciences is particularly interesting. Evaluation frameworks, for example, may constrain the freedom to choose 
research agendas, as institutions may pressure academics into choosing topics that maximise the performance indicators (Martin, 2011). In addition, pressure from managerialism and those related to the 'institutional need' to obtain research grants may aggravate tensions related to the research-teaching nexus (Leisyte, 2016), and a greater availability of research funding is associated with research agendas that are more contained within disciplines and focus on established topics (that can hamper research at disciplinary borders where breakthrough research can occur; Martimianakis and Muzzin, 2015). Institutional pressure focusing on grant competition cause a migration towards safer research, as neither funding nor results are guaranteed for cutting-edge topics (see also Young, 2015) and research funding agencies favour traditional mainstream disciplinary bound research (Siler at al., 2015). Although it is not possible to claim causality using the current research design - or even the direction of such causation - these results support the findings of Leisyte (2007), suggesting that academics respond to increasing uncertainty by 'falling in line' with institutional demands to maintain access to resources, while attempting to maximise work stability. This suggests that the current academic research governance paradigm pushes academics towards more conservative endeavours by encouraging them to pursue such agendas, while only in the absence of such pressure can ground-breaking agendas thrive.

Two further issues are of relevance. The first is the negative impact of unconstraint on divergence and collaboration. This suggests that the lack of pressure to do work unrelated to research activities (as can be the case in teaching) decreases the propensity to engage in multidisciplinary research endeavours and collaborations. This highlights the importance of academics remaining involved in teaching activities and the benefits that teaching can have for research, although the relation is usually 
perceived as being from research to teaching (Hajdarpasic et al., 2015). The second issue concerns the findings associated with willingness to stay and belonging, which have a strong negative effect on divergence and discovery. This suggests that academics who feel 'comfortable' in their current institutions tend to gravitate towards more conservative research agendas. Academics may accommodate and acquiesce to institutional pressure, which is typically manifested as pursuing 'safer' research rather than cutting-edge topics (Young, 2015). This also highlights the difference between academic settings and non-academic settings in which organisational commitment is perceived as a benefit (Madsen et al., 2005). In academic settings, this commitment can have the opposite effect, which underlines the need for mobility so other academic environments and contact with other ideas, knowledge and ways of doing research can be experienced.

In conclusion, the limitations and implications for future studies of this study should be noted. In terms of the limitations, first, it makes use of self-reported survey data. This method has several logistical benefits, as it allows for large-scale data collection exercises in a cost-effective manner. However, it then carries the risk of respondent bias like any survey, typically manifested as socially desirable responses (McDonalds and Ho, 2002). The questions used as a basis for this study are perceptionbased, which means that the participants' responses are based on their individual construction of reality (Lindsay and Norman, 2013). The literature suggests that perceptions tend to align with behaviour (Pickens, 2005), but it is still important to note that potential issues can emerge through this method. This issue was mitigated as the findings of this study rely on two validated measurement instruments. In terms of future research, although this study contributes to a more thorough understanding of the interplay between academics and universities, further work is required as scholars have 
suggested this area is under-researched (Antonelli et al., 2011). From this study, inquiry can extend in three directions. The first is to conduct the same type of analysis in other fields of knowledge and disciplines, which may not be as vulnerable to recent institutional and organisational changes influencing research practices as the social sciences (Hammarfelt and Rushforth, 2017). The second is to consider organisational factors when defining the research agendas of new types of academics, such as entrepreneurial academics, who work alongside 'traditional academics' but who are more active in engaging with partners outside academia (and thus it is more likely that their research agendas are influenced by them), but also engage in practices that position them in overlapping organisational arrangements, leading to a variety of purposes including knowledge exchange and commercialisation (D’Este and Perkmann, 2011). Similarly, the third direction is to focus on those academics who increasingly engage in participatory research and include non-experts and civic communities in their research activities, which can potentially enable them to develop research agendas with a high level of social impact (Doberneck et al., 2010).

\section{References}

Acker, S., and Webber, M. (2017). Made to measure: Early career academics in the Canadian university workplace. Higher Education Research and Development, 36(3): 541-554.

Alexander, A.T., Miller, K., and Fielding, S. (2015) Open for business: universities, entrepreneurial academics and open innovation. International Journal of Innovation Management, 19(6): 1540013. 
Antonelli, C., Franzoni, C., and Geuna, A. (2011) The organization, economics, and policy of scientific research: what we do know and what we don't know-an agenda for research. Industrial and Corporate Change, 20(1): 201-213.

Avolio, B. J., Zhu, W., Koh, W., and Bhatia, P. (2004). Transformational leadership and organizational commitment: Mediating role of psychological empowerment and moderating role of structural distance. Journal of Organizational Behavior, 25(8): 951-968.

Baccini, A., Barabesi, L., Cioni, M., and Pisani, C. (2014) Crossing the hurdle: the determinants of individual scientific performance. Scientometrics 101: 20352062.

Walsh, J.P., and Lee, Y.-N. (2015) The bureaucratization of science. Research Policy 44: $1584-1600$.

Ball, S. J. (2012). Global Education Inc. New policy networks and the neo-liberal imaginary. London: Routledge.

Ball, S. J. (2003). The teacher's soul and the terrors of performativity. Journal of education policy, 18(2), 215-228.

Bandura, A. (1978). The self system in reciprocal determinism. American psychologist, 33(4), 344.

Bazeley, P. (2003). Defining 'early career' in research. Higher Education, 45(3): 257 279.

Bazeley, P. (2010). Conceptualising research performance. Studies in Higher Education, 35(8): 889-903.

Beerkens, M. (2013) Facts and fads in academic research management: the effect of management practices on research productivity in Australia. Research Policy 42: 1679-1693. 
Bourdieu, P. (1999). The specificity of the scientific field. The Science Studies Reader. Ed. Biagioli M. New York: Routledge, 31-50.

Brew, A., and Lucas, L. (2009) Academic research and researchers. Maidenhead: Open University Press.

Carayol, N., and Matt, M. (2004) Does research organization influence academic production? Laboratory level evidence from a large European university. Research Policy 33: 1081-1102.

Castro-Ceacero, D., and Ion, G. (2018). Changes in the university research approach: challenges for academics' scientific productivity. Higher Education Policy, DOI: $10.1057 / \mathrm{s} 41307-018-0101-0$

Cattaneo, M., Meoli, M., and Signori, A. (2016) Performance-based funding and university research productivity: the moderating effect of university legitimacy. Journal of Technology Transfer 41: 85-104.

Chubb, J., and Watermeyer, R. (2017). Artifice or integrity in the marketization of research impact? Investigating the moral economy of (pathways to) impact statements within research funding proposals in the UK and Australia. Studies in Higher Education, 42(12): 2360-2372.

Cummings, J. N., and Kiesler, S. (2005). Collaborative research across disciplinary and organizational boundaries. Social Studies of Science, 35(5): 703-722.

Deem, R., Hillyard, S., and Reed, M. (2008). Knowledge, higher education, and the new managerialism: the changing management of UK universities. London: Oxford University Press.

Degn, L. (2018). Academic sensemaking and behavioural responses - exploring how academics perceive and respond to identity threats in times of turmoil. Studies in Higher Education, 43(2): 305-321. 
D'Este and Perkmann, M. (2011) Why do academics engage with industry? The entrepreneurial university and individual motivations. The Journal of Technology Transfer 36(3): 316-339.

Doberneck, D.M., Glass, C.R., and Schweitzer, J. (2010) From rhetoric to reality: a typology of publically engaged scholarship. Journal of Higher Education Outreach and Engagement, 14(4): 5-35.

Ebadi, A., and Schiffauerova, A. (2015). How to receive more funding for your research? Get connected to the right people! PloS One, 10(7), e0133061.

Edgar, F., and Geare, A. (2013). Factors influencing university research performance. Studies in Higher Education, 38(5): 774-792

Firestein, S. (2015). Failure: Why science is so successful. Oxford: Oxford University Press.

Fox, M.F., and Mohapatra, S. (2007) Social-Organizational characteristics of work and publication productivity among academic scientists in doctoral-granting departments. The Journal of Higher Education 78(5): 542-571.Giroux, H. A. (2016). University in chains: Confronting the military-industrial-academic complex. New York, NY: Routledge.

Hair, J. F., Black, W. C., Babin, B. J., Anderson, R. E., and Tatham, R. L. (2007). Multivariate data analysis. Bookman.

Hajdarpasic, A., Brew, A., and Popenici, S. (2015). The contribution of academics' engagement in research to undergraduate education. Studies in Higher Education, 40(4): 644-657.

Hammarfelt, B., and Rushforth, A. D. (2017). Indicators as judgement devices: An empirical study of citizen bibliometrics in research evaluation. Research Evaluation, 26(3): 169-180. 
Hemlin, S., Allwood, C. M., and Martin, B. R. (2008). Creative knowledge environments. Creativity Research Journal, 20(2): 196-210.

Hicks, D. (2012) Performance-based university research funding systems. Research Policy, 41(2): 251-261.

Hillson, D., and Murray-Webster, R. (2007). Understanding and managing risk attitude. Gower Publishing, Ltd.

Hoffman, D. M., Blasi, B., Ćulum, B., Dragšić, Ž., Ewen, A., Horta, H., and RiosAguilar, C. (2014). The methodological illumination of a blind spot: information and communication technology and international research team dynamics in a higher education research program. Higher Education, 67(4), 473-495.

Horta, H., and Santos, J. M. (2016). An instrument to measure individuals' research agenda setting: the multi-dimensional research agendas inventory. Scientometrics, 108(3): 1243-1265.

Horta, H., and Jung, J. (2014). Higher education research in Asia: An archipelago, two continents, or merely atomization? Higher Education, 68(1): 117-134.

Horta, H., and Lacy, T.A. (2011) How does size matter for science? Exploring the effects of research unit size on academics' scientific productivity and information exchange behaviors, Science and Public Policy 38(6): 449-460

Ion, G., and Castro Ceacero, D. (2017). Transitions in the manifestations of the research culture of Spanish universities. Higher Education Research and Development, 36(2): 311-324.

Júnior, S.K., Borges, R.L.A., and Prince, D. (2018) Scientific production and its collective determinants: an econometric analysis for the Brazilian research labs. Science and Public Policy 45(5): 661-672. 
Kallio, K.-M., and Kallio, T.J. (2014) Management-by-results and performance measurement in universities - implications for work motivation. Studies in Higher Education 39(4): 574-589.

Kyvik, S., and Aksnes, D.W. (2015). Explaining the increase in publication productivity among academic staff: a generational perspective. Studies in Higher Education, 40(8): 1438-1453.

Kwiek, M. (2016) The European research elite: a cross-national study of highly productive academics in 11 countries. Higher Education 71(3): 379-397.

Langfeldt, L., Bloch, C.W., and Sivertsen, G. (2015) Options and limitations in measuring the impact of research grants - Evidence from Denmark and Norway. Research Evaluation, 24(3): 256-270.

Latour, B., and Woolgar, S. (2013). Laboratory life: The construction of scientific facts. Princeton University Press.

Leathwood, C., and Read, B. (2013). Research policy and academic performativity: compliance, contestation and complicity. Studies in Higher Education, 38(8): $1162-1174$.

Lee, Y.-N., Walsh, J.P., and Wang, J. (2015) Creativity in scientific teams: unpacking novelty and impact. Research Policy 44: 684-697.

Leisyte, L. (2007). University governance and academic research: Case studies of research units in Dutch and English universities. University of Twente, Enschede.

Leisyte, L. (2016). New public management and research productivity - a precarious state of affairs of academic work in the Netherlands. Studies in Higher Education, 41(5): 828-846. 
Leisyte, L., and Dee, J. R. (2012). Understanding academic work in a changing institutional environment. In Higher education: Handbook of theory and research (pp. 123-206). Springer.

Leisyte, L., Enders, J., and De Boer, H. (2008). The freedom to set research agendasillusion and reality of the research units in the Dutch universities. Higher Education Policy, 21(3): 377-391.

Levin, J. S., and Aliyeva, A. (2015). Embedded neoliberalism within faculty behaviors. Review of Higher Education, 38(4): 537-563.

Lindsay, P. H., and Norman, D. A. (2013). Human information processing: An introduction to psychology. Academic Press.

Long, J. S., and Krauze, T. K. (1982). Cumulative advantage and inequality in science. American Sociological Review, 47: 615-625

Long, J.T., and McGinnis, R. (1981) Organizational context and scientific productivity. American Sociology Review 46(4): 422-442.

Madsen, S. R., Miller, D., and John, C. R. (2005). Readiness for organizational change: Do organizational commitment and social relationships in the workplace make a difference? Human Resource Development Quarterly, 16(2): 213-234.

Mamun, S. A. K., and Rahman, M. M. (2015). Is there any feedback effect between academic research publication and research collaboration? Evidence from an Australian university. Scientometrics, 105(3): 2179-2196.

Martimianakis, M. A., and Muzzin, L. (2015). Discourses of interdisciplinarity and the shifting topography of academic work: Generational perspectives on facilitating and resisting neoliberalism. Studies in Higher Education, 40(8): 1454-1470.

Martin, B. R. (2011). The Research Excellence Framework and the "impact agenda": are we creating a Frankenstein monster? Research Evaluation, 20(3): 247-254. 
McDonald, R. P., and Ho, M.-H. R. (2002). Principles and practice in reporting structural equation analyses. Psychological Methods, 7(1): 64-82.

Meyer, J. P., and Allen, N. J. (1991). A three-component conceptualization of organizational commitment. Human Resource Management Review, 1(1): 6189.

Mitchell, J. E., and Rebne, D. S. (1995). The nonlinear effects of teaching and consulting on academic research productivity. Socio-Economic Planning Sciences, 29: 47-57.

Mowday, R. T., Steers, R. M., and Porter, L. W. (1979). The measurement of organizational commitment. Journal of Vocational Behavior, 14(2): 224-247.

Munch, R. (2014) Academic capitalism: Universities in the global struggle for excellence. New York: Routledge.

Oleksiyenko, A., and Tierney, W. G. (2018). Higher education and human vulnerability: global failures of corporate design. Tertiary Education and Management, DOI: $10.1080 / 13583883.2018 .1439094$

Olssen, M. (2016). Neoliberal competition in higher education today: Research, accountability and impact. British Journal of Sociology of Education, 37(1): 129-148.

Perkmann, M., Tartari, V., McKelvey, M., Autio, E., Brostrom, A., D’Este, P., Fini, R., Geuna, A., Grimaldi, R., Hughes, A., Krabel, S., Kitson, M., Llerena, P., Lissoni, F., Salter, A., and Sobrero, M. (2013) Academic engagement and commercialization: a review of the literature on university-industry relations. Research Policy 42(2): 423-442. 
Perkmann, M., and Walsh, K. (2008) Engaging the scholar: three types of academic consulting and their impact on universities and industry. Research Policy, 37(10): 1884-1891.

Pickens, J. (2005). Attitudes and perceptions. Organizational Behavior in Health Care, 43-76.

Pinheiro, R., and Stensaker, B. (2014). Designing the Entrepreneurial university: The interpretation of a global idea. Public Organization Review, 14(4): 497-516.

Platow, M. J. (2012). PhD experience and subsequent outcomes: a look at selfperceptions of acquired graduate attributes and supervisor support. Studies in Higher Education, 37(1): 103-118.

Polanyi, M. (2000). The republic of science: Its political and economic theory. Minerva, 38(1): $1-21$.

Postiglione, G. A., and Jung, J. (2015). Congeniality and research productivity in stateprofessional-market driven systems of mass higher education in Cummings, W.K., and Teichler, U. (Eds.) The relevance of academic work in comparative perspective. Dordrecht: Springer (pp. 107-120).

Rammstedt, B., and John, O. P. (2007). Measuring personality in one minute or less: A 10-item short version of the Big Five Inventory in English and German. Journal of Research in Personality, 41(1), 203-212.

Rzhetsky, A., Foster, J. G., Foster, I. T., and Evans, J. A. (2015). Choosing experiments to accelerate collective discovery. Proceedings of the National Academy of Sciences, 112(47): 14569-14574.

Santos, J. M. (2017). Development and validation of the Multi-dimensional University Research Workplace Inventory (MDURWI). Higher Education Policy, 18(3): $381-404$. 
Santos, J. M., and Horta, H. (2018). The research agenda setting of higher education researchers. Higher Education, 76(4): 649-668.

Schrecker, E. (2012). Academic freedom in the corporate university. The Radical Teacher, 93: 38-45.

Siler, K., Lee, K., and Bero, L. (2015). Measuring the effectiveness of scientific gatekeeping. Proceedings of the National Academy of Sciences, 112(2): 360365.

Smith, J. (2017). Target-setting, early-career academic identities and the measurement culture of UK higher education. Higher Education Research and Development, 36(3): 597-611.

Stromquist, N. P. (2017). The professoriate: The challenged subject in US higher education. Comparative Education, 53(1): 132-146.

Sutton, P. (2017). Lost souls? The demoralization of academic labour in the measured university. Higher Education Research and Development, 36(3): 625-636.

Tight, M. (2013) Discipline and methodology in higher education research. Higher Education Research and Development, 32(1): 136-151.

Towns, J., Cockerill, T., Dahan, M., Foster, I., Gaither, K., Grimshaw, A., and Peterson, G. D. (2014). XSEDE: accelerating scientific discovery. Computing in Science and Engineering, 16(5): 62-74.

Verbree, M., Horlings, E., Groenewegen, P., Weijden I.V., and Basselaar, P. (2015) Organizational factors influencing scholarly performance: a multivariate study of biomedical research groups. Scientometrics, 102: 25-49.

Winter, R. (2009). Academic manager or managed academic? Academic identity schisms in higher education. Journal of Higher Education Policy and Management, 31(2): 121-131. 
Woelert, P., and Yates, L. (2015). Too little and too much trust: Performance measurement in Australian higher education. Critical Studies in Education, 56(2): 175-189.

Yokoyama, K. (2006). The effect of the research assessment exercise on organisational culture in English universities: Collegiality versus managerialism. Tertiary Education and Management, 12(4): 311-22.

Young, M. (2015). Competitive funding, citation regimes, and the diminishment of breakthrough research. Higher Education, 69: 421-434. 